\title{
Improving uniform scattering device for straw-smashing, back-throwing, no-tillage planter under complete straw mulching condition
}

\author{
Fengwei Gu, Xuemei Gao, Feng Wu, Zhichao Hu*, Youqing Chen, Chong Zhang \\ (Nanjing Research Institute for Agricultural Mechanization of National Ministry of Agriculture and Rural Affairs, Nanjing 210014, China)
}

\begin{abstract}
With the objective of obtaining a completely straw-mulched field, when no-tillage mechanical sowing is implemented with straw smashing, delivering, and back-throwing approaches, it may be difficult to scatter the smashed straw uniformly during a succeeding wheat sowing step. This is because the previous rice straw is substantial in quantity and has a high humidity and toughness, which may easily result in non-uniform straw mulching and thus sparse and weak seedlings of wheat. Therefore a force-dispersing and uniform-scattering device was designed. With the number of scattering impellers, impeller angle, and impeller rotation speed as the main factors and the percentage of pass for the scattering width and non-uniformity of the straw mulching as the assessment indices, single-factor experiments and orthogonal regressive tests were performed, and a dual-index (percentage of pass for the scattering width and non-uniformity of the straw mulching) fitted regression equation was established. The test results suggested that the main factors (from primary to secondary) that influence the indices were the impeller rotation speed, number of scattering impellers, and impeller angle. The optimal parameter combination for the uniform scattering device was four rows of impellers with an angle of $15^{\circ}$, rotation speed of $1015 \mathrm{r} / \mathrm{min}$, percentage of pass of $72.65 \%$ for the scattering width, and a non-uniformity of $13.8 \%$ in the straw mulching. This combination can be used to realize a uniform scattering of the smashed straw along the seedling rows on the after-sowing ground. According to the field investigation of the wheat growth, the wheat emergence rate was $90.7 \%$. The research results can provide a reference for improving the uniform scattering device for a straw-smashing, back-throwing, no-tillage planter for obtaining a completely straw-mulched field, enhancing the quality of the machinery operation, and ensuring good and strong seedlings after sowing.
\end{abstract}

Keywords: complete straw mulching, no-tillage planter, uniform scattering of straw DOI: $10.25165 /$ j.ijabe.20181106.4597

Citation: Gu F W, Gao X M, Wu F, Hu Z C, Chen Y Q, Zhang C. Improving uniform scattering device for straw-smashing, back-throwing, no-tillage planter under complete straw mulching condition. Int J Agric \& Biol Eng, 2018; 11(6): 49-57.

\section{Introduction}

When sowing is performed in a completely straw-mulched field, where the straw is not collected or disposed after the harvest of the crops, it is wasteful in terms of time and money and inefficient to perform mechanized sowing after gathering and removing the straw. There is high demand among farmers for no-tillage mechanical sowing that does not require the collection or removal of the straw. However, the traditional sowing device encounters various problems, such as straw plugging, seed erecting, and seed drying, when it is operated in a completely straw-mulched field, and it cannot even ensure smooth operation or good sowing quality. Owing to the lack of appropriate machines and tools for achieving no-tillage sowing in a completely straw-mulched field, farmers resort to burning the straw. Therefore, straw burning

\section{Received date: 2018-08-28 Accepted date: 2018-11-20}

Biographies: Fengwei Gu, Associate Research Fellow, research interests: agricultural mechanization, Email: gfwsll@163.com; Xuemei Gao, Engineer, research interests: agricultural machinery design, Email: 591882839@qq.com; Feng Wu, Associate Research Fellow, research interests: agricultural mechanization, Email: 5446770@qq.com; Youqing Chen, Associate Research Fellow, research interests: agricultural mechanization, Email: 89081229@ qq.com; Chong Zhang, Master candidate, research interests: agricultural machinery design, Email: 985147419@ qq.com.

*Corresponding author: Zhichao $\mathrm{Hu}, \mathrm{PhD}$, Research Fellow, research interests: agricultural device research. Nanjing Research Institute for Agricultural Mechanization, Ministry of Agriculture and Rural Affairs, Nanjing 210014, China. Tel: +86-15366092908, Email: zchu369@163.com. occurs repeatedly despite its prohibition ${ }^{[1,2]}$.

In a preliminary study, a no-tillage sowing machine that can realize "straw-smashing," "lifting-for-delivering," and "back-throwing" operations was developed. In addition, it was able to break the straw barriers in order to move forward as well as prevent the seeds from falling into the soil and being covered by it. The machine could complete the sowing, fertilization, and soil-covering operations in areas that were free of straw barriers and could scatter the smashed straw over the ground after the sowing operation. Furthermore, it resolved the difficulties of straw plugging, seeds not coming into contact with the soil, and seeds remaining uncovered by soil. It could also complete the no-tillage sowing of wheat in a completely straw-mulched field of peanut, corn, or rice crops in a single round ${ }^{[3-8]}$.

During the aforementioned operation in a rice-wheat rotation area, owing to the large amount and high toughness of the straw after the harvesting of rice, it is difficult to scatter the seeds uniformly, which may result in non-uniform straw mulching and even sparse and weak growth of wheat seedlings ${ }^{[1]}$. Therefore, there is a high demand for uniform scattering of smashed rice straw $^{[9]}$. As there are no existing studies on the uniform scattering of seeds in a completely rice straw-mulched field, in this work, a force-dispersing and uniform-scattering device was designed independently based on a pre-stage developed machine ${ }^{[10-12]}$. Moreover, a dual-index (percentage of pass for the scattering width and non-uniformity of the straw mulching) fitted to a regression equation is established based on a single-factor experiment and 
combined test. In addition, an optimization analysis of the uniform scattering device is performed to provide the basis for improving it for realizing straw-smashing, back-throwing, no-tillage planting in a completely straw-mulched field; a uniform coverage of the smashed straw over the ground after the planting; straw incorporation; and preservation of heat and moisture and for ensuring good and strong crop seedlings ${ }^{[13-17]}$.

\section{Structure and design of uniform scattering device}

\subsection{Structure and operating principle of uniform scattering} device

The straw-smashing, back-throwing, no-tillage planter used in completely straw-mulched fields comprises three components: a device for smashing and throwing the straw, a device for residual cutting and shallow rotating, and a device for sowing and fertilizing $^{[3]}$. In addition, with flexible combination technology, fast switching and convenient equipping can be realized according to the various crop-planting demands. The operating principle of the machine is as follows: to collect and smash the straw in the field; deliver it upward and backward; pass it over the sowing and fertilizing device and throw it backward; cut the residue and perform a shallow rotation in the barrier-free area formed while picking up and putting down the straw; sow, fertilize, and earth-up; and scatter the smashed straw on the ground along the seedling row.

The aforementioned procedures of smashing, collecting, and delivering the straw, and scattering straw over the ground after sowing are realized by the device used for the smashing, collecting, delivering, and throwing of the straw shown in Figure 1. It comprises main frame 2 , the regulating parts-limit-depth straw pressing wheel 1 and straw crossing board 4-and the operating parts-straw smashing device 3, straw throwing device 5, straw lifting device 6 , and scattering device 7 .

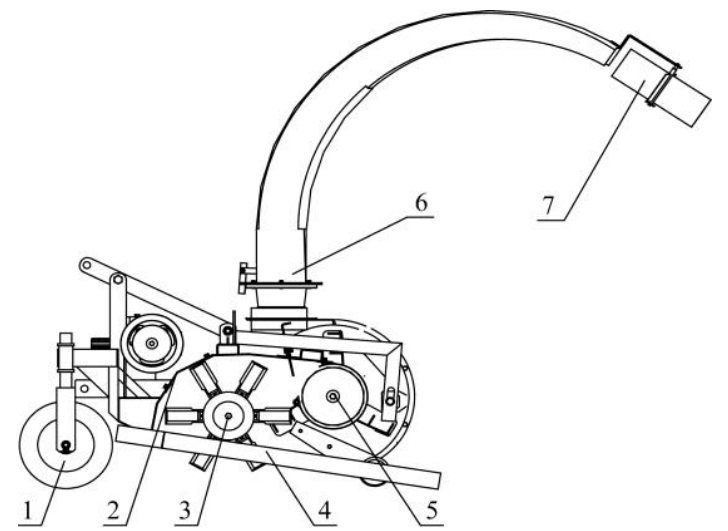

1. Limit-depth straw pressing wheel 2. Main frame 3. Straw smashing device

4. Straw crossing board 5. Straw collecting device 6. Straw lifting device 7. Scattering device

Figure 1 Structural diagram of the straw-smashing, back-throwing device

During the operation, the limit-depth straw pressing wheel rolls over the rice straw beyond the operation width, and the straw crossing board coordinates in order to press the straw to ensure that the machine can cross the rice straw beyond the operation width smoothly. Concurrently, the straw smashing device smashes the rice straw and residuals within the operation width and transports them to the collecting device. The smashed straw is delivered to straw lifting device 6, and after fertilizing, sowing, and earthing-up, the smashed straw is scattered by the scattering device on the ground after the planting. In this manner, no-tillage wheat planting is completed in a completely rice straw-mulched field.

2.2 Structural design of uniform scattering device and equipping position

The smashed straw is thrown directly from the end of straw lifting device 6 (Figure 1), but owing to the pneumatic force of the pipe, the smashed straw is concentrated and is paved in strips. This strip pavement and clustering coverage may result in non-uniform coverage of the straw, which is unfavorable for heat and moisture preservation, and would cover the seedlings tightly, thus adversely affecting the seedling and growth of the wheat. Therefore, a force-dispersing and uniform-scattering device is required to be designed to realize a uniform scattering of the smashed straw on the ground after the planting.

The assembly drawing of the uniform scattering device is shown in Figure 2. Scattering impeller 1 has a hollow casing structure and is installed on rotary shaft 2. Various forms of scattering impellers can be used based on the different types of preceding-crop straw. Rotary shaft 2 is fixed at the end of delivery pipe 4 of the straw lifting device by a connecting support plate 3. During operation, the scattering impeller can realize high-speed rotation under the pneumatic force of the delivery pipe, separate the smashed straw, and scatter it uniformly on the field after the planting.

The above non-power, passive rotary design can meet the demands of the no-tillage planting of corn and peanuts in a completely wheat straw-mulched field. However, when planting wheat in a completely rice straw-mulched field having rice-wheat rotation areas, as the rice straw is substantial in quantity and has a high moisture and toughness, the device is unable to disperse it, and thus, a power-driven active rotating device is designed. On selecting speed-regulating motor 6 and connecting it to the top of rotary shaft 3 using a flexible shaft, power-driven active rotation is realized by the scattering impeller, and the rotation speed can be regulated.

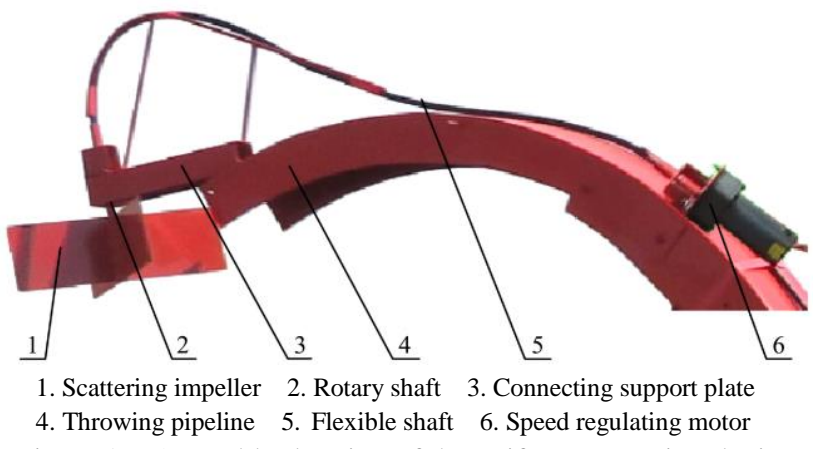

Figure 2 Assembly drawing of the uniform scattering device

\section{Single-factor experiment of key parameters of uniform scattering device}

To ensure the uniform scattering of the smashed straw, the structure of the scattering device and its structural and motion parameters should be optimized through an experiment.

\subsection{Experimental design}

\subsubsection{Experimental method and assessment index design}

The straw-smashing, back-throwing, no-tillage planter can plant 12 rows at a time in a completely straw-mulched field. If it only ensures excessive dispersion for achieving uniform scattering of the smashed straw in a single step and scatters excessive smashed straw beyond the effective sowing width, it may result in an overlapping straw coverage of adjacent rows, which would 
affect the seedlings. Consequently, it should be ensured that uniform straw scattering is realized with an effective sowing width, i.e., the 12-row planting zone should be uniformly covered with the smashed straw. Therefore, two indices, namely, percentage of pass for the scattering width $P$ and straw coverage non-uniformity $F$, are employed to represent the uniform scattering performance of the planter.

As rare studies conducted on the uniform straw scattering performance in a completely rice straw-mulched field, the calculation formula for the percentage of pass for the scattering width $P$ is obtained based on a practical operation:

$$
P=\frac{M_{1}}{M_{2}} \times 100
$$

where, $M_{1}$ is the straw mass beyond the single-stroke 12-row planting zone (i.e., the effective sowing width shown in Figure 3-the width between the midpoints of $A B$ and $C D$ ), $\mathrm{g}$, and $M_{2}$ is the total mass in and out of the effective sowing width, i.e., the total mass of the straw in the actual scattering width, $g$.

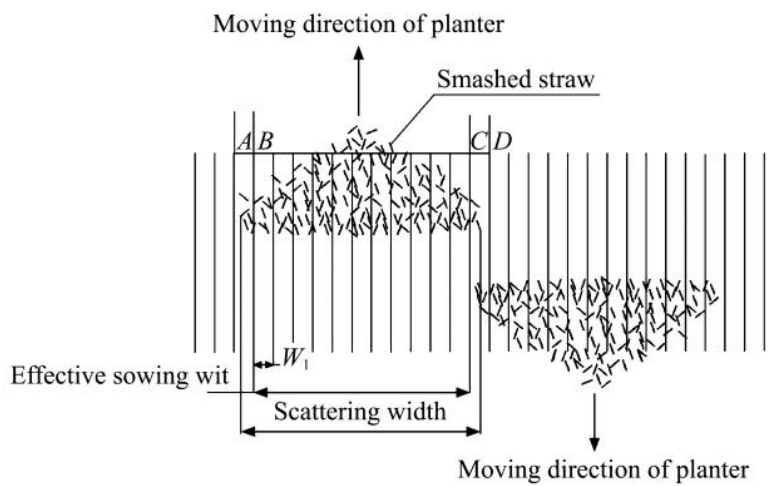

Figure 3 Sketch map of the scattering width

The scattering width is determined based on the effective sowing width of the device, and it is 12 rows each time for sowing wheat. The sowing width is $1800 \mathrm{~mm}$ (section $B C$ in Figure 3), and the width between two sowing rows $W_{1}$ is $164 \mathrm{~mm}$. To ensure that the straw can be scattered uniformly in the 12-row planting zone, i.e., within the effective sowing width, the theoretical scattering width should be larger than $1964 \mathrm{~mm}$ (width between the midpoints of $A B$ and $C D$ in Figure 3) and smaller than $2128 \mathrm{~mm}$ (section $A D$ in Figure 3).

As there are no specific standards for a no-tillage planting operation in a completely straw-mulched field, the national standard "Conservation Tillage Equipment-Smashed Straw Machine" (GB/T 24675.6-2009) is referred to for the calculation of the straw coverage non-uniformity $F^{[18,19]}$ as expressed in Equations (2) and (3). The test method of F used may be referred to in the industrial standard: "Operation Quality of Smashed Straw Machine" (NY/T 500-2015) and "Discussion of the Scattering Non-uniformity Test Method of Smashed Straw Machine" ${ }^{\text {[20,21]. }}$

$$
\begin{gathered}
\bar{M}=\frac{\sum_{i=1}^{n} M_{i}}{n} \\
F=\frac{1}{\bar{M}} \sqrt{\frac{\sum_{i=1}^{n}\left(M_{\mathrm{i}}-\bar{M}\right)^{2}}{n-1}} \times 100
\end{gathered}
$$

where, $n$ is the number of test areas, and to determine whether the straw covers the sowing row uniformly more accurately, $n=6 ; M_{\mathrm{i}}$ is the straw mass of the $i^{\text {th }}$ test area $\mathrm{g} ; \bar{M}$ is the average straw mass of all the test areas $\mathrm{g}$; and $F$ is the percentage of the straw coverage non-uniformity.

\subsubsection{Experimental conditions}

The experiment was conducted at the experimental base of the Nanjing Research Institute for the Agricultural Mechanization, Ministry of Agriculture and Rural Affairs. The moisture content of the straw obtained from the preceding rice harvest is $65 \%$, paved manually in the simulation field, and the density is $2 \mathrm{~kg} / \mathrm{m}^{2}$. The scattering uniformity was measured using a high-speed camera on the planter.

\subsection{Structure and parameters of scattering impeller}

Owing to the varying bio-physical characteristics and the amount of the previous crop straw ${ }^{[15-17]}$, the form of the scattering impeller and number of blades must be designed such that they can be adapted to ensure uniform scattering of straw within the effective sowing width.

\subsubsection{Structure of scattering impeller}

Figure 4a shows the plate impeller. With respect to the previous-crop wheat and corn straw, owing to the small straw quantity, low humidity and toughness, and non-clustering of the scattered straw, it can be learnt from the pre-stage experiment that the plate scattering impeller can be used to realize uniform scattering of the straw. The percentage of pass for the scattering width is over $70 \%$, whereas the straw coverage non-uniformity ranges between $12 \%$ and $17 \%$, which meets the demands.

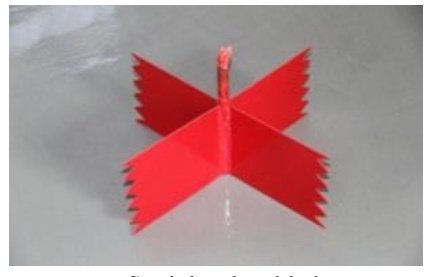

a. Straight-plate blade

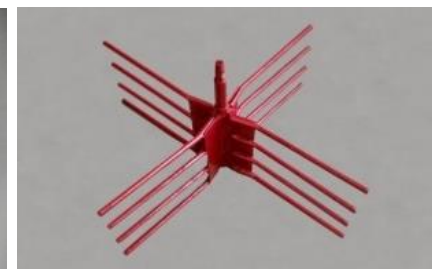

b. Pole-tooth blade
Figure 4 Straight-plate and pole-tooth scattering impellers

The rice straw quantity is much larger than those of the wheat and corn straws ${ }^{[22]}$; in addition, it has high moisture and toughness and clusters after being smashed, and thus, a uniform straw coverage is not obtained owing to the clustering. Therefore, the scattering impellers of other scattering devices fail to ensure uniform straw scattering ${ }^{[23-27]}$, and instead, a pole-tooth scattering impeller is designed as shown in Figure $4 \mathrm{~b}$, which can disperse the clusters and realize dispersion and scattering by utilizing a tearing force.

The scattering effects of the smashed rice straw were compared and studied with various scattering impeller structures using a high-speed camera, and the obtained results are showed in Figure 5.

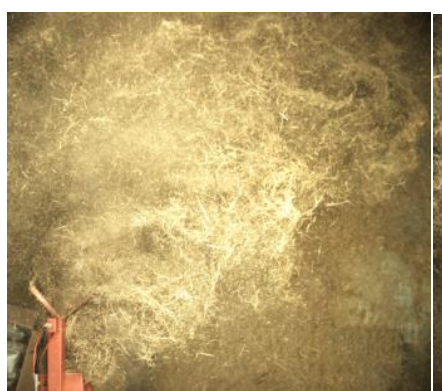

a. Effect of four straight-plate scattering impellers

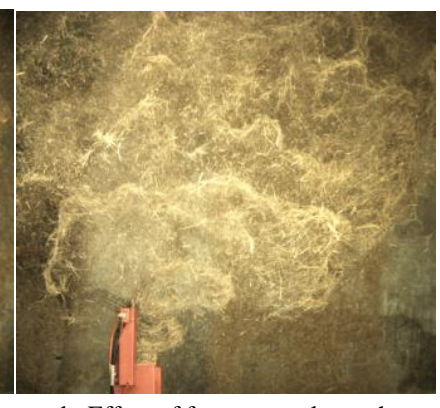
scattering impeller b. Effect of four-row pole-tooth

Figure 5 Straw-scattering effect of plate type and pole-tooth type scattering impeller 
It can be observed from the figure that when the experimental conditions such as the rotation speed of the rotary shaft and number of blades are the same, the two forms of the impeller exhibit different effective scopes of straw scattering, i.e., they have distinct scattering widths. The pole-tooth type has the form of a scattered rounded quadrangle, comprising four layers of intersecting steel bars, which forms three layers of space, such that the scattered straw is distributed in layers. In comparison, a straight-plate impeller has a conical shape in the scattering range, and there is no sense of depth in the plate distribution. According to the test results, the percentage of pass for the scattering width of the plate and pole-tooth impellers is $72.21 \%$ and $70.46 \%$, respectively, whereas the straw coverage non-uniformity is $19.14 \%$ and $14.74 \%$, respectively.

Although the liquidity of straw is much lower than those of fertilizers and seeds because it is a long and flexible material that may become inter-tangled, the above test results are observed because, once the straw encounters the high-speed rotating pole-tooth impeller, it is dispersed easily and scattered uniformly on the ground under the tearing force of the blade. However, the force of the plate impeller is much lower. Despite the high force of the pole tooth impeller, the percentage of pass for its scattering width is slightly smaller than that of the plate impeller, and its straw coverage non-uniformity is also lower. Based on the comprehensive analysis, the pole-tooth impeller exhibits a better uniform scattering performance than the plate impeller for the large-quantity and high-moisture and toughness rice straw.

\subsubsection{Number of scattering impellers}

Based on the qualitative analysis, the use of numerous scattering impellers implies a high frequency of hitting during the straw scattering and lower non-uniformity of the straw coverage. However, in contrast with bulk materials such as fertilizers, the straw may become inter-tangled and form clusters after being smashed. The use of a greater number of scattering impellers also results in a smaller space for smashing. Furthermore, the large quantity of rice straw clusters would not be thrown in a timely manner after being delivered to the scattering impeller, which would lead to plugging and adversely affect the smooth operation. In addition, if the hitting frequency is extremely high, the smashed straw would be easily scattered beyond the effective sowing width, and the device would fail to meet the operation requirement.

To determine the optimal number of impellers, refer to the number of impellers in a fertilizer distributor ${ }^{[25-27]}$; the rotation speed of the fixed rotary shaft is $1000 \mathrm{r} / \mathrm{min} ; 3,4,5,6$, and 8 aclinal straight-bar scattering impellers are selected for the single-factor experiments; and the obtained results are listed in Table 1.

The experimental results show that a larger number of impellers results in a lower non-uniformity. When there are three rows of impellers, the inter-blade space is large, and some smashed straw may be missed when the front blade has already rotated and the behind blade has not come forward yet, thus resulting in greater non-uniformity. When there are eight rows of impellers, the non-uniformity is lower and there is no plugging, but a large amount of smashed straw falls beyond the effective sowing width, and thus, the straw coverage of the planting area cannot be ensured. Therefore, the subsequent experiments should take into consideration an increase in the number of impellers to realize a uniform straw coverage within the effective sowing width when the rotation speed decreases.
Table 1 Results of the single-factor tests under various conditions

\begin{tabular}{|c|c|c|c|c|}
\hline $\begin{array}{l}\text { Number of } \\
\text { scattering } \\
\text { impellers }\end{array}$ & $\begin{array}{l}\text { Scattering } \\
\text { impeller } \\
\text { angle } /\left(^{\circ}\right)\end{array}$ & $\begin{array}{c}\text { Scattering } \\
\text { impeller rotation } \\
\text { speed } / \mathrm{r} \cdot \mathrm{min}^{-1}\end{array}$ & $\begin{array}{c}\text { Percentage of pass } \\
\text { for the scattering } \\
\text { width } / \%\end{array}$ & $\begin{array}{l}\text { Non-uniformity } \\
\text { of the straw } \\
\text { coverage/\% }\end{array}$ \\
\hline 3 & \multirow{5}{*}{0} & \multirow{5}{*}{1000} & 22.11 & 87.53 \\
\hline 4 & & & 16.47 & 73.06 \\
\hline 5 & & & 15.29 & 64.19 \\
\hline 6 & & & 14.03 & 59.82 \\
\hline 8 & & & 10.14 & 50.36 \\
\hline \multirow{5}{*}{4} & -30 & \multirow{5}{*}{1000} & 17.38 & 55.27 \\
\hline & -15 & & 15.96 & 66.91 \\
\hline & 0 & & 14.26 & 69.14 \\
\hline & 15 & & 13.72 & 73.47 \\
\hline & 30 & & 13.18 & 76.89 \\
\hline \multirow{5}{*}{4} & \multirow{5}{*}{0} & 800 & 25.79 & 89.75 \\
\hline & & 900 & 21.25 & 87.23 \\
\hline & & 1000 & 16.01 & 67.91 \\
\hline & & 1100 & 13.07 & 63.43 \\
\hline & & 1200 & 10.88 & 55.08 \\
\hline
\end{tabular}

3.2.3 Angle of scattering impeller

With reference to the slant design of the scattering impeller of a fertilizer distributor and powder gun, four rows of fixed pole-tooth blades and four toothed bars are placed in each row, and the rotation speed of the rotary shaft is $1000 \mathrm{r} / \mathrm{min}$. The single-factor experiment was performed for various angles of each row of the toothed bar, and the sketch map of the impeller angle $\theta$ is shown in Figure 6. Various angles were used with downward angle $\left(\theta=-30^{\circ},-15^{\circ}\right)$, no angle $\left(\theta=0^{\circ}\right)$, and upward angle $(\theta=$ $\left.15^{\circ}, 30^{\circ}\right)$, and the obtained experimental results are listed in Table 1.
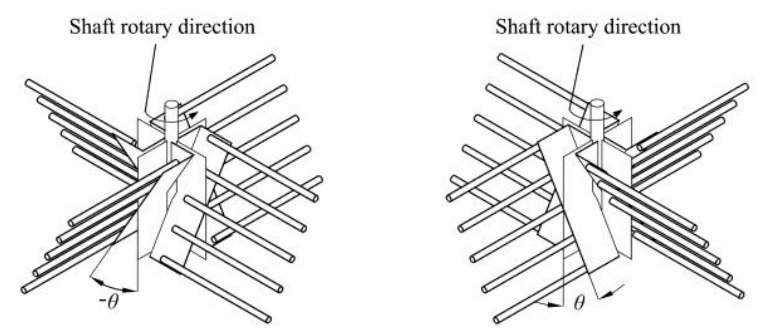

a. Scattering impeller downward angle b. Scattering impeller upward angle

Figure 6 Design of scattering impeller angle $\theta$

According to the experimental results, with constant changes in the upward and downward angles of the impeller, the non-uniformity decreases gradually. When $\theta=-30^{\circ}$, it reaches $25.79 \%$, but when $\theta=30^{\circ}$, despite the lower non-uniformity, substantial smashed straw is thrown beyond the effective sowing width. In addition, when the downward angle is extremely large, the time for the straw to fall to the ground is shortened, such that the straw may be scattered before it is completely dispersed, and thus, the non-uniformity becomes significant. When the upward angle is extremely large, as the smashed straw is driven by the upward toothed bars, it would not be able to fall to the ground in a parabolic form on encountering the toothed bar; instead, it would be thrown to the inclined top and then fall to the ground, which may increase the time of falling. Concurrently, it is carried forward by the toothed bar. Thus, though the straw is uniformly scattered, the percentage of pass for the scattering width is decreased. Consequently, angle $\theta$ should range between $-15^{\circ}$ and $15^{\circ}$. 


\subsection{Motion parameters of scattering impeller}

The main motion parameter impacting the straw coverage uniformity of the scattering device is the rotation speed. If it is extremely high, the straw may be easily scattered beyond the effective sowing width, but if it is extremely low, it may not be able to ensure uniform coverage over the planting row. It can be learnt from the preliminary experiment that when the form and number of scattering impellers is the same, owing to the large amount and high moisture and toughness of the rice straw, the rotation speed of the scattering impeller is also set to a high value. With the four-row aclinal scattering impeller, the active rotating motor was assembled based on the practical conditions by combining the no-load speed and driving force during the non-power passive rotation. The rotation speeds of $800 \mathrm{r} / \mathrm{min}$, $900 \mathrm{r} / \mathrm{min}, 1000 \mathrm{r} / \mathrm{min}, 1100 \mathrm{r} / \mathrm{min}$, and $1200 \mathrm{r} / \mathrm{min}$ are selected for the single-factor experiment, and the experimental results are listed in Table 1.

According to the experimental results, with the rotation speed increased, the non-uniformity reduced. Aiming at the rice straw in the experiment, when the rotation speed was $800 \mathrm{r} / \mathrm{min}$, although nearly $90 \%$ of the straw is scattered within the effective sowing width, the clustering straw it is not dispersed sufficiently, and thus, the non-uniformity of the straw coverage is significant. When the speed increased to $1200 \mathrm{r} / \mathrm{min}$, a substantial amount of straw is scattered beyond the effective sowing width, and thus, the rotation speed should range between $900 \mathrm{r} / \mathrm{min}$ and $1100 \mathrm{r} / \mathrm{min}$.

\section{Comprehensive optimization experiment for operation parameters of scattering device}

The structural and motion parameters that may impact the uniform straw coverage mainly include the number of scattering impellers $n$, scattering impeller angle $\theta$, and rotation speed $r$. It can be understood from the preliminary test that with the increase in the number of impellers and rotation speed, the straw hitting frequency is enhanced, which would decrease the non-uniformity of the straw coverage. However, if the two parameters increase significantly, the straw may be scattered beyond the effective sowing width, i.e., the percentage of pass for the scattering width would be extremely low. A combination of the impeller angle, number of impellers, and rotation speed could potentially be used to realize the least non-uniformity and highest percentage of pass within the effective sowing width. Therefore, a comprehensive optimization experiment should be conducted to obtain an optimal parameter combination.

\subsection{Experimental preparation}

The comprehensive optimization experiment of the operation parameters of the scattering device and single-factor experiment were conducted simultaneously. Therefore, the experimental methods, conditions, and assessment indices are consistent with the previous single-factor experiment, which is not discussed further here.

\subsection{Experimental scheme and results}

Based on the previous single-factor experiment, the number of scattering impeller $n$, scattering impeller angle $\theta$, and rotation speed $r$ are considered as the experimental factors. Whereas the percentage of pass for the scattering width (hereinafter referred to as the percentage of pass for width) $Y_{1}$ and non-uniformity of the straw coverage $Y_{2}$ are the assessment indices for designing a three-factor three-level quadratic regression experiment ${ }^{[28-30]}$. The experimental factors and level design are listed in Table 2, and the experiment scheme and results are presented in Table 3.
Table 2 Factors and levels of the response surface test

\begin{tabular}{lcccccc}
\hline \multirow{2}{*}{ Factor } & \multirow{2}{*}{$\begin{array}{c}\text { Actual } \\
\text { value }\end{array}$} & $\begin{array}{c}\text { Code } \\
\text { value }\end{array}$ & & \multicolumn{3}{c}{ Levels } \\
\cline { 5 - 7 } & & & -1 & 0 & 1 \\
\hline Number of scattering blades/pieces & $Z_{1}$ & $X_{I}$ & 4 & 5 & 6 \\
Scattering blade angle/( $\left(^{\circ}\right)$ & $Z_{2}$ & $X_{2}$ & -15 & 0 & 15 \\
Scattering blade rotation speed/r. $\mathrm{min}^{-1}$ & $Z_{3}$ & $X_{3}$ & 900 & 1000 & 1100 \\
\hline
\end{tabular}

Table 3 Experimental design and response values

\begin{tabular}{|c|c|c|c|c|c|}
\hline \multirow[b]{2}{*}{ No. } & \multirow{2}{*}{$\begin{array}{c}\text { Number of } \\
\text { scattering } \\
\text { impellers } \\
X_{1}\end{array}$} & \multirow{2}{*}{$\begin{array}{c}\text { Scattering } \\
\text { impeller } \\
\text { angle } \\
X_{2}\end{array}$} & \multirow{2}{*}{$\begin{array}{c}\text { Scattering } \\
\text { impeller } \\
\text { rotation } \\
\text { speed } \\
X_{3}\end{array}$} & \multicolumn{2}{|c|}{ Response values } \\
\hline & & & & $\begin{array}{l}\text { Percentage of pass } \\
\text { for the scattering } \\
\text { width } Y_{1} / \%\end{array}$ & $\begin{array}{c}\text { Straw coverage } \\
\text { non-uniformity } \\
Y_{2} / \%\end{array}$ \\
\hline 1 & 0 & 0 & 0 & 63.74 & 16.53 \\
\hline 2 & -1 & -1 & 0 & 66.39 & 17.57 \\
\hline 3 & 0 & 0 & 0 & 63.36 & 15.67 \\
\hline 4 & 0 & 1 & 1 & 56.88 & 13.01 \\
\hline 5 & 0 & 0 & 0 & 62.91 & 15.71 \\
\hline 6 & -1 & 0 & -1 & 88.43 & 21.19 \\
\hline 7 & 1 & 1 & 0 & 57.21 & 13.55 \\
\hline 8 & -1 & 0 & 1 & 62.78 & 12.56 \\
\hline 9 & 0 & -1 & 1 & 51.18 & 13.98 \\
\hline 10 & -1 & 1 & 0 & 73.58 & 14.39 \\
\hline 11 & 0 & 0 & 0 & 69.32 & 15.24 \\
\hline 12 & 1 & 0 & 1 & 57.75 & 12.79 \\
\hline 13 & 1 & -1 & 0 & 61.35 & 12.58 \\
\hline 14 & 1 & 0 & -1 & 70.69 & 17.06 \\
\hline 15 & 0 & -1 & -1 & 78.63 & 19.56 \\
\hline 16 & 0 & 1 & -1 & 71.89 & 17.65 \\
\hline 17 & 0 & 0 & 0 & 62.48 & 15.75 \\
\hline
\end{tabular}

4.3 Establishment and verification of assessment index regression model

The experimental results in Table 2 are analyzed using the Box-Behnken test principle of Design-Expert 8.0.6 ${ }^{[31-33]}$. The response surface models of $Y_{1}$ and $Y_{2}$ are established through multiple regression fitting, as expressed in Equations (4) and (5). Concurrently, the significance test was performed for the equation and regression coefficient of the model, as presented in Table 3, and the final response surface model is determined. Furthermore, the influence law of the interaction between the factors for the indices was analyzed using the response surface analysis method.

$$
\begin{aligned}
Y_{1}= & 63.71-5.41 X_{1}-6.25 \times 10^{-3} X_{2}-10.11 X_{3}-2.96 X_{1} X_{2}+ \\
& 3.04 X_{1} X_{3}+2.94 X_{2} X_{3}+2.92 X_{1}^{2}-2.26 X_{2}^{2}+3.26 X_{3}^{2} \\
Y_{2}= & 15.78-1.22 X_{1}-0.64 X_{2}-2.89 X_{3}+1.04 X_{1} X_{2}+ \\
& 1.09 X_{1} X_{3}+0.24 X_{2} X_{3}-0.7 X_{1}{ }^{2}-0.55 X_{2}{ }^{2}+0.82 X_{3}{ }^{2}
\end{aligned}
$$

As shown in Table 4, the significance value $p$ of $Y_{1}$ and $Y_{2}$ in the response surface model is $p<0.0001$ and $p=0.0001$, respectively, and the $p$ value of the lack of fit was 0.2341 and 0.9069 , respectively, suggesting that the regression model was highly significant and the respective equations had a high fitting degree. Consequently, the operation parameters of the uniform scattering device can be optimized using this model.

The significant factors (in the primary and secondary sequence) impacting $Y_{1}$ are $X_{3}, X_{1}, X_{1} X_{3}, X_{2} X_{3}, X_{3}^{2}, X_{1}^{2}$, and $X_{1} X_{2}(p<0.05)$, and only $X_{2}$ and $X_{2}^{2}$ have an insignificant impact on $Y_{2}$. Similar to $Y_{1}$, the insignificant factors are removed in sequence from the original fitting equation to simplify the equation, and the equation is reexamined. According to the results, the step-by-step elimination and elimination of two insignificant factors would 
reduce the $p$ value of the lack of fit of the simplified equation. Consequently, to ensure a better fitting effect of the regression model, all the factors are retained for the final regression model of $Y_{2}$.

Table 4 Variance analysis of regression equation

\begin{tabular}{|c|c|c|c|c|c|c|c|c|}
\hline \multirow{2}{*}{ Source } & \multicolumn{4}{|c|}{$Y_{1}$} & \multicolumn{4}{|c|}{$Y_{2}$} \\
\hline & Sum of squares & Degrees of freedom & $F$ value & Significant level $p$ & Sum of squares & Degrees of freedom & $F$ value & Significant level $p$ \\
\hline Model & 97.13 & 9 & 32.97 & $<0.0001$ & 1265.57 & 9 & 27.48 & 0.0001 \\
\hline$X_{1}$ & 11.83 & 1 & 36.15 & 0.0005 & 243.98 & 1 & 47.68 & 0.0002 \\
\hline$X_{2}$ & 3.24 & 1 & 9.89 & 0.0163 & 0.51 & 1 & 0.099 & 0.7626 \\
\hline$X_{3}$ & 66.82 & 1 & 204.11 & $<0.0001$ & 821.14 & 1 & 160.48 & $<0.0001$ \\
\hline$X_{1} X_{2}$ & 4.31 & 1 & 13.15 & 0.0084 & 32.09 & 1 & 6.27 & 0.0407 \\
\hline$X_{1} X_{3}$ & 4.75 & 1 & 14.52 & 0.0066 & 40.39 & 1 & 7.89 & 0.0262 \\
\hline$X_{2} X_{3}$ & 0.22 & 1 & 0.67 & 0.4385 & 38.69 & 1 & 7.56 & 0.0285 \\
\hline$X_{1}^{2}$ & 2.09 & 1 & 6.37 & 0.0396 & 32.28 & 1 & 6.31 & 0.0403 \\
\hline$X_{2}^{2}$ & 1.29 & 1 & 3.94 & 0.0874 & 26.28 & 1 & 5.14 & 0.0578 \\
\hline$X_{3}^{2}$ & 2.86 & 1 & 8.73 & 0.0213 & 32.58 & 1 & 6.37 & 0.0396 \\
\hline Lack of fit & 1.42 & 3 & 2.17 & 0.2341 & 4.19 & 4 & 0.18 & 0.9069 \\
\hline Pure error & 0.87 & 4 & & & 31.62 & 4 & & \\
\hline Total & 99.43 & 16 & & & 1301.39 & 16 & & \\
\hline
\end{tabular}

In this model, the significant factors (in the primary and secondary sequence) impacting $Y_{2}$ are $X_{3}, X_{1}, X_{1} X_{3}, X_{1} X_{2}, X_{2}, X_{3}^{2}$, and $X_{1}^{2}(p<0.05)$, and only $X_{2}^{2}$ and $X_{2} X_{3}$ have an insignificant impact on $Y_{1}$. To simplify the equation, the insignificant factors are eliminated stepwise from the original fitting equation, and the equation is then reexamined. The results show that the $p$ value of the lack of fit decreases when only $X_{2}^{2}$ is eliminated or two insignificant factors are eliminated, and it increases when $X_{2} X_{3}$ is eliminated. Therefore, only $X_{2} X_{3}$ is eliminated from the final regression model of $Y_{1}$.

To resolve the regression equation conveniently, the optimal index and parameter combination is obtained, and the code values of the parameters of the final regression model of $Y_{1}$ and $Y_{2}$ are converted to the actual values. Therefore, the final regression models established in this study are given in Equations (6) and (7).

$$
\begin{aligned}
Y_{1}= & 699.537-64.9875 z_{1}-1.11242 z_{2}-0.81649 z_{3}-0.18883 z_{12}+ \\
& 0.031775 z_{1} z_{3}+2.07333 \times 10^{-3} z_{2} z_{3}+2.769 z_{1}^{2}-0.011104 z_{2}^{2}+ \\
& 2.7815 \times 10^{-4} z_{3}^{2} \\
Y_{2}= & 170.0425-5.07875 z_{1}-0.38825 z_{2}-0.24185 z_{3}+0.069167 z_{1} z_{2}+ \\
& 0.0109 z_{1} z_{3}-0.70375 z_{1}{ }^{2}-2.46111 \times 10^{-3} z_{2}^{2}+8.2375 \times 10^{-5} z_{3}^{2}
\end{aligned}
$$

\subsection{Effect of interaction on assessment index}

The influence law of a single factor on the assessment index has been stated previously. To obtain the optimal parameter combination and analyze the relation between the factors and assessment indices more directly, the response curve of the impact of the interaction of two factors on an index is drawn based on the above comprehensive experiment using Design-Expert 8.0.6.1, as displayed in Figure 7. The effect of the interaction between two factors on an index is analyzed with the third factor as the center.

(1) Analysis of influence law of interaction on percentage of pass for sowing width

Figures $7 \mathrm{a}-7 \mathrm{c}$ present the response surface curves of the effect of the interaction between two factors on the percentage of pass for the sowing width. The figures show that the angles in the three curves are different, which suggests that the distinct interactions have varying impacts on the index. The angles in Figures $7 \mathrm{~b}$ and 7c differ slightly, but the $Y_{1}$ value which in Figure $7 \mathrm{~b}$ has a larger fluctuation than the Figure 7c. It shows that $X_{1} X_{3}$ has a significant effect on the index, which is obviously greater than that of $X_{2} X_{3}$.
The result is consistent with Table 4 . It can be seen from Table 4 $X_{1} X_{2}$ has a lesser effect than the interaction between the other two factors, the curve is relatively flat. The general influence laws of the factors for the percentage of pass for the sowing width are as follows: a greater number of impellers implies a larger angle, and a higher rotation speed implies a smaller percentage of pass for the sowing width; else the percentage of pass for the sowing width will be higher. This is also consistent with the results of the previous single-factor experiments.

(2) Analysis of influence law of interaction for straw coverage non-uniformity

Figures 7d-7f display the response surface curves of the impact of the interaction between two factors on the straw coverage non-uniformity. Similar to the analysis of the effect of the interactions between two factors on the percentage of pass for the sowing width, according to these figures, a slanted surface in Figures $7 \mathrm{~d}$ and $7 \mathrm{e}$ is more evident than in Figure 7f, which suggests that the interaction between $X_{1} X_{2}$ and $X_{1} X_{3}$ has a more significant impact on the index than $X_{2} X_{3}$. This is consistent with Table 4, according to which $X_{1} X_{3}$ and $X_{1} X_{2}$ have a significant effect on the index, whereas $X_{2} X_{3}$ has an insignificant impact on the index. Concurrently, the general influence law can also be determined from the figure: a greater number of impellers implies a larger angle, and a higher rotation speed corresponds to a lower straw coverage non-uniformity; else, the straw coverage non-uniformity will be higher. This is also consistent with the results of the previous single-factor experiment.

\subsection{Comprehensive optimization solution of parameters for assessment indices}

To realize a relatively optimal uniform scattering performance, the percentage of pass for the scattering width is required to be high and the straw coverage non-uniformity should be low. Based on the above experimental analysis, a smaller number of impellers corresponds to a smaller angle and a lower rotation speed implies a higher percentage of pass for the sowing width. With respect to the straw coverage non-uniformity, a greater number of impellers corresponds to a larger angle, and a higher rotation speed implies a lower non-uniformity. Therefore, the effects of the factors on the two assessment indices should be combined, and the optimization 
solution is obtained for the complete factorial secondary regression model (straw coverage non-uniformity and percentage of pass for the sowing width) established in this study using Design-Expert 8.0.6.1.

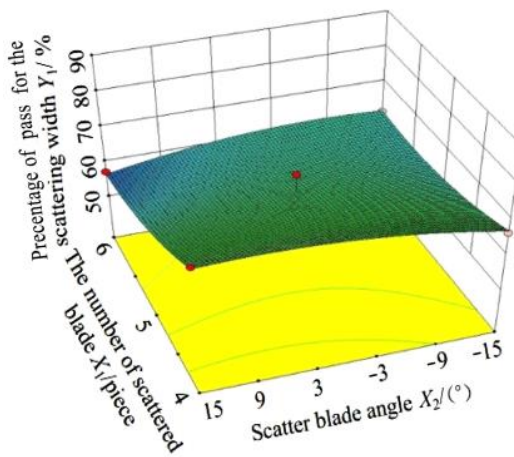

a. $Y_{1}=f\left(X_{1}, X_{2}, 0\right)$

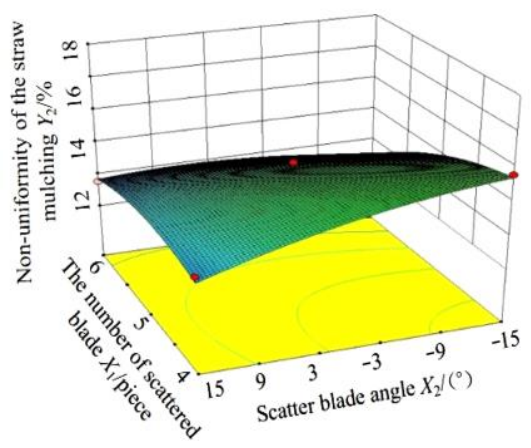

d. $Y_{2}=f\left(X_{1}, X_{2}, 0\right)$

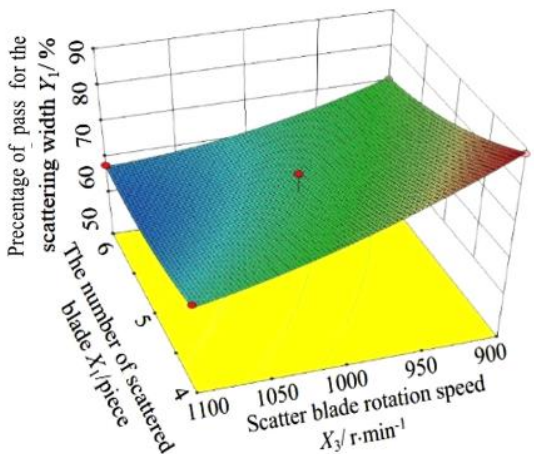

b. $Y_{1}=f\left(X_{1}, 0, X_{3}\right)$

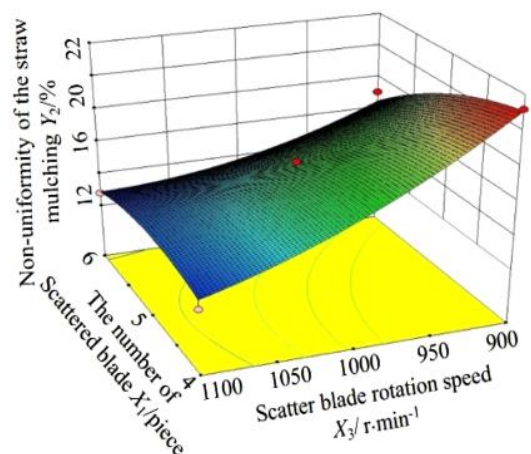

e. $Y_{2}=f\left(X_{1}, 0, X_{3}\right)$

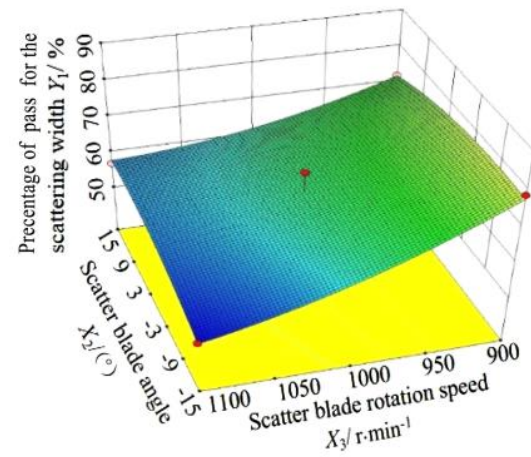

c. $Y_{1}=f\left(0, X_{2}, X_{3}\right)$

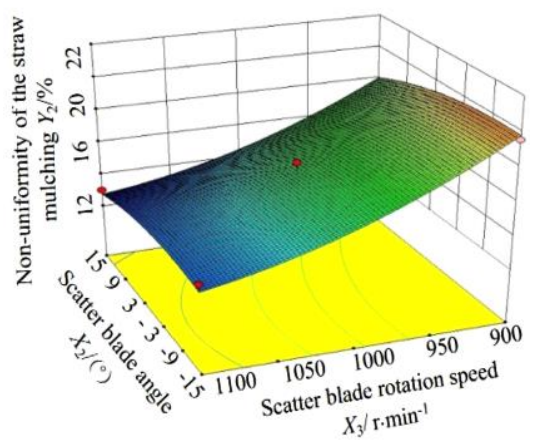

f. $Y_{2}=f\left(0, X_{2}, X_{3}\right)$

Figure 7 Effects of the interaction between the factors on the percentage of pass for the scattering width and straw coverage non-uniformity

The constraint conditions are 1) target function: $\max Y_{1}, \min Y_{2}$, and 2) range of the variables: $-1 \leq X_{j} \leq 1$, where $j=1,2,3$. The optimal parameter combination obtained from the optimization solution is as follows: four rows of impellers, upward angle of impeller of $15^{\circ}$, and rotation speed of $1015 \mathrm{r} / \mathrm{min}$. The theoretical optimization value of the percentage of pass for the sowing width is $71.73 \%$ and of the straw coverage non-uniformity is $13.51 \%$, which is similar to the tenth group of the experimental scheme of the response surface design scheme, i.e., four rows of the impellers, upward angle of the impeller of $15^{\circ}$, and rotation speed of $1000 \mathrm{r} / \mathrm{min}$. To verify the optimization results and fitting model, a field experiment verification should be performed with the optimal parameter combination.

\section{Field experiment and wheat seedling condition}

\subsection{Field experiment verification}

The experiment site is the Liuhe experiment base of the Jiangsu Academy of Agricultural Sciences, and the experiment conditions are those for a completely straw-mulched field wherein the rice stalks are paved, as shown in Figure 8, the moisture content of the straw is $62 \%$ and straw yield is $2.22 \mathrm{t} / \mathrm{hm}^{2}$.

Using the optimal parameter combination, i.e., four rows of impellers, upward angle of the impeller of $15^{\circ}$, and rotation speed of $1015 \mathrm{r} / \mathrm{min}$, the experiment is repeated thrice, as depicted in Figure 9, to obtain the percentage of pass for the scattering width and straw coverage non-uniformity, and the mean value is considered as the experimental verification result. The actual values of the percentage of pass and straw coverage non-uniformity are $72.65 \%$ and $13.80 \%$, respectively, which satisfy the operational requirements.

\subsection{Wheat seedlings in field}

Based on the field experiment, the wheat seedlings after sowing are tracked, as illustrated in Figure 10. Under the measured percentage of pass $72.65 \%$ and non-uniformity $13.80 \%$, sparse seedlings are not obvious in the wheat field, and the measured seedling rate is $90.7 \%$, which indicates good growth.

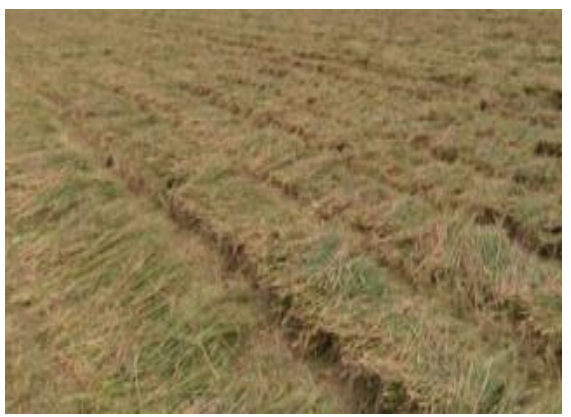

Figure 8 Complete stalk spread of the rice straw in the field before sowing

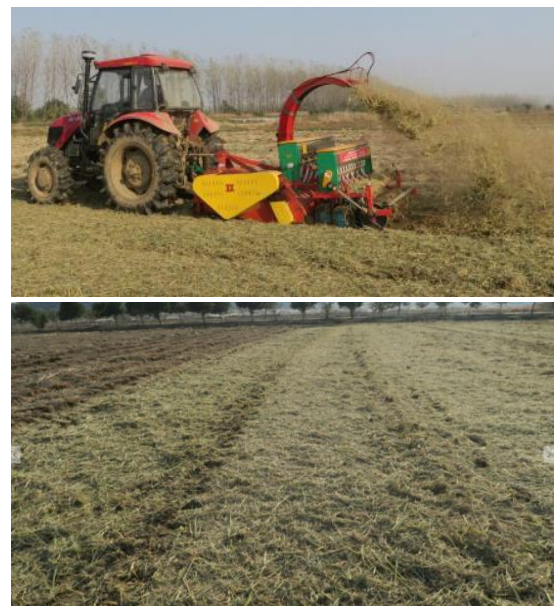

Figure 9 Field experiment and work effect 


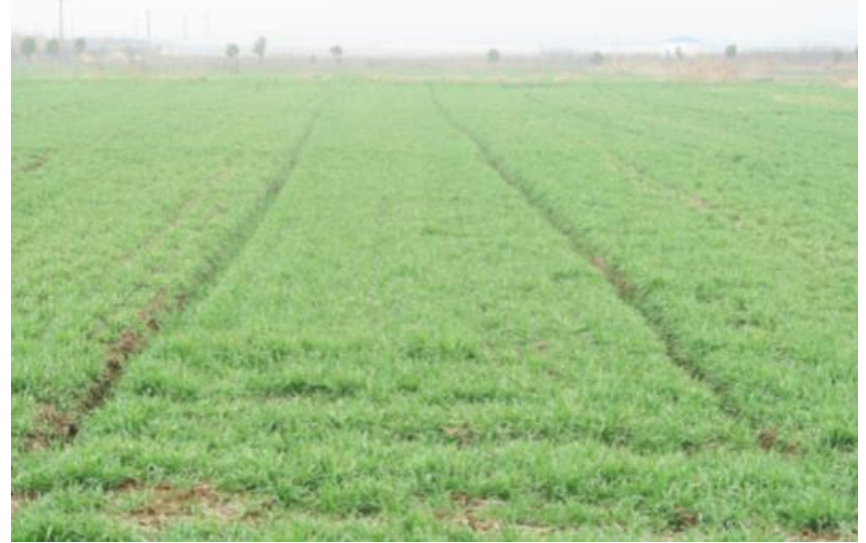

Figure 10 Wheat seedling situation

\section{Conclusions}

(1) In order to solve the tightly-covered and sparse-seedling problems caused by the large quantity of rice straw, its significant toughness, easy clustering after being smashed, and difficulty in uniform scattering with a straw-smashing, back-throwing, no-tillage planter in a completely straw-mulched field, an active rotating force-dispersing and uniform-scattering device is designed. This device can be used to scatter the smashed straw uniformly along the sowing row on the ground after the planting. The high-speed-camera single-factor experiment analysis shows that the pole-tooth scattering impeller achieves a better straw coverage uniformity than the straight-plate scattering impeller.

(2) It is determined from the analysis that the number of impellers, impeller angle, and rotation speed are the main factors affecting the uniformity of the straw coverage. Furthermore, on the premise that there are no distinct standards, related standards of a smashed straw machine are referred to. The percentage of pass for the scattering width and straw coverage non-uniformity are adopted for the first time to represent the operational performance of the scattering device.

(3) Using a combination of single-factor and comprehensive experiments, a double-index (percentage of pass for the scattering width and straw coverage non-uniformity) fitting regression equation is established. Accordingly, the factors (in a sequence from primary to secondary) affecting the two indices are clarified as follows: rotation speed, number of impellers, and impeller angle. Concurrently, the optimal parameter combination of the key scattering parts is determined, namely, a rotation speed of the pole-tooth scattering impeller of $1015 \mathrm{r} / \mathrm{min}$, four rows of impellers, and an impeller upward angle of $15^{\circ}$. Using this combination, the straw coverage effect is optimal, percentage of pass is $72.65 \%$, and non-uniformity is $13.80 \%$. According to the growth track, the seedling rate of the wheat field is $90.7 \%$, and it is free from evident sparse seedlings and has a good growth.

(4) The straw-smashing, back-throwing, no-tillage planter realizes smooth no-tillage operation in a completely straw-mulched field. The force-dispersing and uniform-scattering device researched in this study achieves uniform straw scattering when there is a large amount of preceding rice straw, but there are various factors affecting the seedlings and growth of the crops.

In a subsequent research, we will study and realize a regulated proportion of "straw buried and covering" in a completely straw-mulched field from a mechanical perspective to ensure good and strong seedlings of wheat after they are sowed in the preceding rice straw field.

\section{Acknowledgements}

This research work is a part of the Special funding project of National Modern Agricultural Peanut Industrial Technology System Construction (CARS-14-mechanical equipment); buried fruit harvester of the innovation project of Chinese Academy of Agricultural Sciences.

\section{[References]}

[1] Gürsoy S. Performance evaluation of the row cleaner on a no-till planter Transactions of the ASABE, 2014; 57(3): 709-713.

[2] Bagnall G, Thomasson J, Ge Y. Animal-drawn conservation-tillage planter designed for small farms in the developing world. Appl. Eng. Agri. 2016; 32(6): 791-799.

[3] Gu F, Hu Z, Chen Y, Wu F. Development and experiment of peanut no-till planter under full wheat straw mulching based on "clean area planting". Transactions of the CSAE, 2016; 32(20): 15-23. (in Chinese)

[4] Liu F. Study on cultivation mode of no-tillage direct-seeding rapeseed (Brassica napus L.) based on rich straw mulching. Wuhan: Huazhong Agricultural University, 2012. (in Chinese)

[5] Li A, Fan X, Wu C, Li H. Situation and development trends of conservation tillage in the world. Transaction of CSAM, 2006; 37(10): 177-180. (in Chinese)

[6] $\mathrm{Hu} \mathrm{Z}$. Great breakthrough in the research and development of the mechanical no-tillage planter technology in full straw mulching field. Prim. Agr. Technol. Extn., 2015; 4: 40.

[7] Gu F, Hu Z, Tin L, Ji F, Wang H. General situation and development of peanut mechanization planting in China. Jiangsu Agr. Sci., 2010; 3 : 462-464. (in Chinese)

[8] Chen Y, Wu F, Gu F, Wang B, Ma B, Hu Z. Test on peanut no-till planter under the coverage of the wheat straw. J. Chin. Agr. Mechanization, 2014 35(2): 132-135. (in Chinese)

[9] Zhang S, Gu K, Zhang H, Gu D, Zhang C, Yang S. Effects of tillage and sowing patterns on wheat seedling emergence and yield with rice straw returning. Chin. Agr. Sci. Bull. 2017; 33(10): 19-22. (in Chinese)

[10] $\mathrm{Hu} \mathrm{Z,} \mathrm{Wu} \mathrm{F,} \mathrm{Gu} \mathrm{F,} \mathrm{Chen} \mathrm{Y,} \mathrm{Wang} \mathrm{B.} \mathrm{A} \mathrm{no-tillage} \mathrm{wheat} \mathrm{planter} \mathrm{with}$ adjustable amount of straw coverage in the full straw mulching field: China, ZL201410113918.7. 2016-7-20. (in Chinese)

[11] Hu Z, Chen Y, Wu F, Cao M, Liu M. An improved device of straw outlet of the straw-smashing, fertilizing, sowing and straw covering machine: China, ZL201210472637.1. 2014-12-24. (in Chinese)

[12] Hu Z., Xu H, Cao M, Wang S, Yu Z. A device of pneumatic transmission and uniform scattering of particle materials: China, ZL201510566793.8. 2017-3-22. (in Chinese)

[13] Alford S. Cover crop and no-till effects on soil health properties in Indiana. Purdue University, 2015.

[14] McGrath D, Smith C, Gholz H, Oliveira F. Effects of land-use change on soil nutrient dynamics in Amazonia. Eco. 2001;4(7): 625-645.

[15] Taboada M, Micucci F, Cosentino D, Lavado R. Comparison of compaction induced by conventional and zero tillage in two soils of the Rolling Pampa of Argentina. Soil Till. Res., 1998; 49(1): 57-63.

[16] Pierce F, Fortin M-C, Staton M. Periodic plowing effects on soil properties in a no-till farming system. Soil Sci Soc America, 1994; 58(6): 1782-1787.

[17] Sørensen L. Organic matter and microbial biomass in a soil incubated in the field for 20 years with 14C-labelled barley straw. Soil Biol. Biochem, 1987; 19(1): 39-42.

[18] GB/T 24675.6-2009. Conservation tillage equipment - Smashed straw machine.

[19] Zhang X, Gao X, Chen T, Wang A, Wang H. Study on improvement and experiment for the nozzle of 4BQD-40 pneumatic spraying seeding-machine. J. Agr. Mechanization Res. 2013; 3: 188-191. (in Chinese)

[20] NY/T500-2015. Operation quality of smashed straw machine. (in Chinese)

[21] Sun L, Feng J. Research on test method of straw scattering inhomogeneity for smashed straw machine. J. Chin. Agr. Mechanization, 2016; 37(6): 35-38. (in Chinese)

[22] Zhang F, Zhu Z. Harvest index for various crops in China. Sci. Agri Sin., 1990; 23(3): 83-87. (in Chinese)

[23] Bi Y, Gao C, Wang Y, Li B. Estimation of straw resources in China. 
Transactions of the CSAE, 2009; 25(12): 211-217. (in Chinese)

[24] Zhong H, Yue Y, Fan J. Characteristics of crop straw resources in China and its utilization. Res. Sci., 2003; 25(4): 62-67.

[25] Wu H. Development and distribution study on the spreading test system for a spinner spreader. Baoding: Agricultural University of Hebei, 2007. (in Chinese)

[26] Dong X, Song J, Zhang J, Kang X, Wang J. Working performance and experiment on granular fertilizer spreader with cone disk. Transactions of CSAE, 2013; 29(19): 33-40. (in Chinese)

[27] Lü J, Shang Q, Yang Y, Li Z, Li J, Liu Z. Performance analysis and experiment on granular fertilizer spreader with cone disc. Transactions of CSAE, 2016; 32(11): 16-24. (in Chinese)

[28] Hu Z. Study on key technologies of half-feed peanut combine harvester. Beijing: China Agricultural Science and Technology Press, 2013. (in
Chinese)

[29] Yuan Z, Yun H. Experiment design and analysis. Beijing: China Agriculture Press, 2007. (in Chinese)

[30] Chen K. Experiment design and analysis. Beijing: Tsinghua University Press, 2005. (in Chinese)

[31] Ge Y. Experimental design method and application of design-expert software. Harbin: Harbin Institute of Technology Press, 2014. (in Chinese)

[32] Yan W, Hu Z, Wu N, You Z, Zhou X. Parameter optimization and experiment for plastic film transport mechanism of shovel screen type plastic film residue collector. Transactions of the CSAE, 2017; 33(1): 17-24. (in Chinese)

[33] You Z, Wu H, Chen Y, Hu Z, Tan L, Peng B, et al. Design and experiment on double-sieve-driving apparatus for film-soil separation and transportation. Int. Agr. Eng. J., 2018; 27(2): 378-387. 